\title{
Learner Open Modeling in Adaptive Mobile Learning System for Supporting Student to Learn English
}

\author{
http://dx.doi.org/ijim.v5i4.1789 \\ Viet Anh NGUYEN and Van Cong PHAM \\ University of Engineering and Technology, VNU, Hanoi, Vietnam
}

\begin{abstract}
This paper represents a personalized contextaware mobile learning architecture for supporting student to learn English as foreign language in order to prepare for TOEFL test. We consider how to apply open learner modeling techniques to adapt contents for different learners based on context, which includes location, amount of time to learn, the manner as well as learner's knowledge in learning progress. Through negotiation with system, the editable learner model will be updated to support adaptive engine to select adaptive contents meeting learner's demands. Empirical testing results for students who used application prototype indicate that interaction user modeling is helpful in supporting learner to learn adaptive materials.
\end{abstract}

Index Terms-m-learning, context-awareness, personalized learning, open learner modeling

\section{INTRODUCTION}

Because of it s portability, mobile technology is a growing trend in a wide range of activities in modern life such as: co mmunication, entertainment, banking and education. Therefore, mobile learning is also emerging as important research in e-learning field. One of the be nefits of mobile learning (m-learning) is the ability to provide and access learning $\mathrm{m}$ aterials anytime in a nywhere. For two decades, Adaptive Hypermedia (AH) syste ms have been developed to provide the learners with adaptive learning materials based o $\mathrm{n}$ their demands through evaluating learner model. Most AHs are des igned for the personal computers, so it requ ires a definite location and time. Having restricted location and time, the learners find it difficult to approach the learning systems whenever they need. Consequently, the most recent generation of mobile learning research focuses on context-aware mobile learning application. With adaptive engine usages, the learners can e asy browse the adapted course content as they want.

Our research addresses the context-awareness adaptation in mobile learning that aims to support Vietnamese students to use the mobile devices such as mobile phone, Personal Digital Assistant (PDA) to learn English in order to prepare for TOEFL test. We are interested in the learner modeling as well as th e context factors that affect the students. In addition, we take into account open learner modeling to obtain user information as get the learner to talk the system what they need to know. An improved prototype of our model, CAMLES [1] system also described.
The main contribution of our work is personalized learning materials by using open learner modelling to support the learners can edit their model through negotiation with the system. The rest of this paper is structured as fo llows: First, we rev iew the related researches on context-aware location dependent learning. In the next section, the context factors using in our model to adapt course content for each student is introduced. As for the fourth section, we represent our c ontext-aware mobile learning, the CAMLES system that focuses on representing how to manage editable learner model and content model as wel 1 as the system design and architecture. System implementation with our experiments will also be described in sectio $\mathrm{n}$ five. Finally, the discussions and conclusions are summarized.

\section{LITERATURE REVIEW}

Our literature review presen ts recent context-aware $\mathrm{m}$ learning applications for 1 earning language. Especially, those support students to learn foreign languages. These applications can be classified into two categories: contextaware location-independent learning and context-aware location-dependent learning. Learners can use the form er anywhere that is not restricted in any speci fied locations. The later application, through location-tracking technologies such as GPS or WLAN, which can automatically identify the learner's location as selec ting appropriate learning resources for them, is especially basic. Now, we focus on several typical applications:

- CAMCLL [ 2], context-aware location-independent learning, teaches Chinese to the students whose language levels are not enough to make conversations in Chinese by supporting appropriate sentences to different learners based on contexts. The CAMCLL context includes time, location, activities and learner levels. Adaptive engine of CAMCLL is based on ontology and rule-based matching.

- TenseITS [3] teaches English language to foreign students through meeting their demands. Learner model is designed based on $\mathrm{f}$ our context factors: location, interruption/distraction, concentration and available time. Appropriate learning materials for different learners are selected based on the information represented in learner model.

- LOCH [4], context-aw are location-dependent learning, supports students to learn Japanese whi le involving in real time situations. By monitoring the positions of the learners, teachers can establish the 
communication with the students and g uide them. The context factor in LOCH system is location.

- English vocabulary learning [5] recommends vocabulary for different learners based on their location, time for their learning and individual abilities. This system uses WLAN to identify learner's position. In addition, it uses some techniques such as maximizing information strategy, evaluating the score of $t$ ime characteristics and estimating the amount of learning words to select suitable vocabulary for different learners.

- TANGO [6] supports Japanese students to identify English words with physical objects via the use of mobile devices through RFID tag reader/writer. TANGO includes six modules to select appropriate English words based on learner models.

- MESLL [7] is designed to support Japanese learners to learn Kanji or Chinese as a second language via SMS function or e mail. The learne rs send an e mail to the system in order to request a test. The system composes a test and feedbacks to them including adaptive English words as well as example sentences.

- PALLAS [ 8] is desi gned to support to a mobile language learner by providing personalized and contextualized access to learning resources which is considered as a part of cont extualization. Personalization of the system has been defined based on learning style preferences, learner's objectives, and current learner's knowledge.

\section{CONTEXT FACTORS TO ADAPT}

Context is an $y$ information that can be used to characterize the situation of an entity such as a person, place or object that is considered relevant to the interaction between a user and an application [9]. Meanwhile, according to $\mathrm{B} . \mathrm{Hu}$, in m-learning, context is the set of suitable environmental states and settings based on situated roles between a learner and a tutor [10].

In our personalized m-learning model, it is suggested that context is the information that has impact on learners in learning activities. We assume that there are several factors having influence on adapt ing course materials in each learner. Location, tim e, manner, and learne r's knowledge are context factors taken into account in our model. Firstly, location allows information and services to localize. In our model, location allows adaptation system to situated place where learners participate in the course. As S.Cui proposed in TenseITS [3], location is a sp ecial place where students use $m$ obile devices to learn such as home, bus terminal, hotel, etc. Secondly, time refers to the instantaneous time of the day. Specially, the interval that the learner interacts with the system is important for an amount of course materials requiring the learners to learn. Thirdly, the manner of learning is considered as a factor of context using for adaptation. It mentions learner's attitudes such as concentration, interest level when they take part in the course. Finally, learner's knowledge is regarded as an oriental factor to determine what course content should be learned in the next stage.

Context-awareness describes a process in which context factors are us ed to target the provision of adaptive learning materials for the learner in interactive systems based on location, learner's preferences as well as learner's knowledge. This process includes two principal functions: 1) context interpretation and 2) con text implementation
[11]. The $f$ ormer collects the learner's input data. Following context processing, the later issues the output that is personalized according to the information reflecting learner modeling.

Reichenbancher [12] noted that there are four different levels of adaptation: information level, technology level, user interface level and pres entation level. Focusing on information level, our model aims to adapt learning materials according to context factors mentioned above. In the next section, we will $p$ resent our personalized mobile learning framework in deeply.

\section{CONTEXT AWARE MOBILE LEARNING ARCHITECTURE}

In order to select personalized mobile learning materials based on the c ontext as well as learner' s preferences, we propose architecture with their layers described in Figure 1.

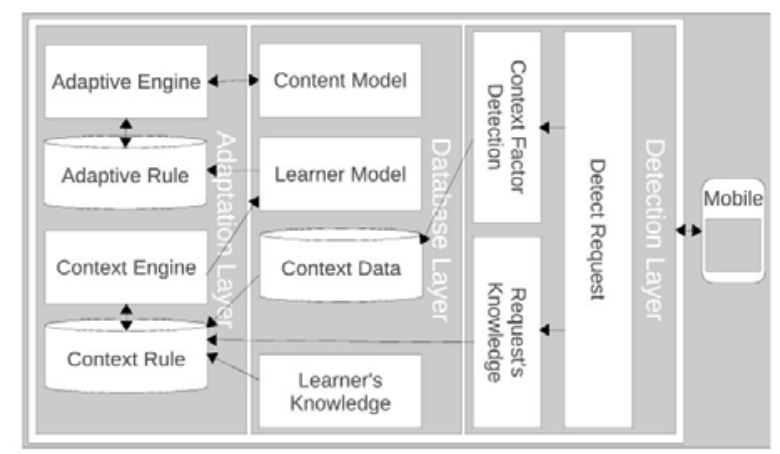

Figure 1. Context-Aware mobile learning architecture

\section{A. Detection Layer}

The function of the detection layer is to define the requirements of learners, in cluding the normal acade mic requirements or requests to change the assessment system for learners. Requirements normal learning behaviour of learners choose topics, the context in which the system offers, then the system will generate learning content compatible with the choices av ailable to the learners. For the normal academic requirements, the request will b e determined through the identification of contextual factors that the user input options, such as lo cation, time and learning topics. These factors made the user interface to the learner can choose. $T$ he elements are selected according to the person standi ng position and the ti me he or she can learn. This requi rement is applicable to learners, when they choose new $\mathrm{t}$ opic or $\mathrm{i} n$ the new context. Besides, requests to change the assess ment system for learners are required to change indicator of the level of understanding of the learner after the implementation of the normal acade mic requirements of learner completed. That is, it was onl y made when learners complete their learning content through the test questions. For this requirement, students must pay through an examination and assessment of the learning process in the system. Request is the response of learners to assess learning outcomes after the end of learning content that the system made based on normal academic requirements above. This requirement is a change in the knowledge of the topics that the learners who participate. Therefore, when learners make this re quest means that the learner wants to change the level of knowledge in the database to 
achieve a high level of knowledge than reality. In addition to giving context and gat her feedback from learners, detection layer includes a test for eval uation of the first learn to participate in the system.

\section{1) Detect Request}

This component is responsible for classifying requests that learners interact with the system. The system is divided into two types of entry requirements:

- Firstly, the requirements in terms of context, when the learner needs in terms of learning content, the request will be passed to the component Context Factor Detection for processing.

- Secondly, the requirements in terms of changes in the level of knowledge of learners for each topic, which the system was ra ted after the y complete learning content. Learning content is delivered by systems through data collection requirements on the context in which learners choose.

In addition, the data request is processing the request on a proficiency test, like tests of assessm ents of the candidates qualifications.

\section{2) Context Factor Detection}

For a syste $\mathrm{m}$ of learning English in context, the determination of the input context elements is a first step in the processing system. Context Factor Detection is part of the Detection Layer, its function is to identify the contextual factors which the user provides the system to start their learning process. In this context is defined, including the location of the user, the time that they can be used to complete the required course content and i ts concentration in the learning process. Each person can learn at the same location or different. Similarly, they can have time to learn the same or di fferent. The concentrations are separate. In general, we can say that each individual has a separate context, most of the m are different. Therefore, the composition Context Detection Factor was born with the specific task of determining the value of the components that the context user supplied. These values are i nput to the system's data layer. This component works only when there is interaction in terms of context between users and syste ms. That is, in the process of learning, learner does not have any changes in terms of 1 ocation, duration and concentration, the components will not make it to redefine these elements. Then, the de fault factors pr ovided the context for the system is the contextual factors that considered as users' first choice in the process of using the system. In other words, the component Context Detection Factor referred to as user requirements change in terms of location, time or concentration.

\section{3) Request's Knowledge}

After each learning content, learners must complete a test. The syste $\mathrm{m}$ will asses $\mathrm{s}$ understanding of content learned through the course of the test results. Results of evaluation of the system can not satisfy learners. The learner might think that their level of understanding of that field as well, wh ile the system is rated at normal levels. Therefore, they will not agr ee with this assessment, they want to change this assessment, they want their system to assess the level of unde rstanding of content. Then, they asked to change their level of understanding about that field. When learners have this requirement, the Data Request to transfer the request to the Request Knowledge.
This component is responsible for processing the request to change the understanding of a topic in which the learner has participated. This component is re quired to receive input from learners on updating the assessment of their knowledge about the topic just to participate. The update is a change in their data in the database system. It involves elements corresponding to the context that they are topics to change 1 evels of underst anding. Hence, it will be combined with contextual elements that learners initially are available to the system. This combination will be held in Adaptation Layer. Th us, the composition Request's Knowledge update request to change data on the level of understanding of the learner to provide treatment system. When learners participate in the system and make learning content, the composition Request's Knowledge can be used several times, repeated until the learner to accept the assessment of the system on the level of knowledge of person for each subject participated.

\section{B. Database layer}

Database layer is a component of the system where data is stored and provided to the system. This layer consists of four subcomponents: context data, learner's knowledge, learner model and co ntent model. The com ponents are closely linked together. Firstly, the context is separated into two co mponents, including data about the context (location and time) and data about the learner's knowledge before. The separation into two components will support the processing system to update the knowledge required from the user feedback better. The system will only have to update the knowledge level of users wi thout having to change the context of their pr evious selections. Learner's knowledge, which stores information about the assessment system for learners. This is the level of knowledge learned at the end of his studies. Secondly, the learner m odel and content model are two ingredients which are base $d$ on rules adapted from that extract the relevant content, stored in a database, users and interactive learning.

\section{1) Context data}

Context information is the information obtained from the learner's request such as location, interval of time to learn and concentration. These factors require the learners to fill in before they participate in the course. In this model, we define location as a place where the learners use mobile devices to take part in the course. It is no $t$ a specific common place such as home, bus terminal, hotel, etc. Each location is described by a corresponding discrete value in Table 1 . This represents the factors that impact on learning activities such as co ncentration level, the frequency interruption as well as available time to learn. The lower va lue indicates that the location affecting context factors is higher, whereas the higher value indicates that impact is lower.

\section{TABLE I. THE VALUE OF LOCATION FACTOR}

\begin{tabular}{|c|l|c|}
\hline No & \multicolumn{1}{|c|}{ Location } & Value \\
\hline 1 & Bus terminal & 1 \\
\hline 2 & Restaurant & 2 \\
\hline 3 & Outing & 3 \\
\hline 4 & Campus & 4 \\
\hline 5 & Home & 5 \\
\hline
\end{tabular}


Interval of time is available time that the learner will spend on learning. In terms of time limit in using mobile device, we $u$ se four options of interval of $t$ ime for choosing the time to learn. These are 15, 30, 45, and 60 minutes. Similarly, we use discrete values to identify the level of concent ration. The learner can choose one of parameters before pa rticipating in the course. T hose values are only used to as sume the concentration of learner because selection ca nnot guarantee for that the learners will concentrate as they do.

The concentration parameter is designed to determine the learner's requirements of concent ration on 1 earning while student uses mobile device to browse the course. Three concentration levels are low, medium and hi gh. Each of them also is described by discrete value that is 1 , 2 and 3 respectively.

\section{2) Learner's Knowledge}

Learner's Knowledge is the user's knowledge of the topics given in the system. This knowledge is the result obtained by two methods:

- Firstly, it is the result of the learning process. This result is determined by: after each lesson content, the system will give a cert ain number of questions. Then the user will complete the questions. The system is b ased on the amount of questions that users complete right to make the rate of assess ment for each topic that the learner has chosen. This rate will 1 be reported to the learner. If the learner does not accept the rate of assessment, or it is the knowledge that the system offers, the user may change that assessment in accordance with their ca pabilities. The system will rely on feedba ck data and the previous context, generates a set of questions for users to complete. The system will re-evaluate and inform students. Notification process - feedba ck loop is done, only when the learner accepts the level of knowledge that the system evaluated.

- Secondly, the initial test of their knowledge of learners without their contents must complete a co urse before. A set of questions will be generated automatically and randomly covers the most basic themes that initially the user needs to achieve. The com pletion of these questions and received feedback is determined similarly to the above method.

Knowledge of the learner after the unification and was saved in the database will b e divided into five basic levels: poor, average, good, very good, excellent. Each level also is described by discrete value as sho wed in Table 2.

TABLE II. LEVEL KNOWLEDGE LEVEL

\begin{tabular}{|c|l|c|}
\hline No & \multicolumn{1}{|c|}{ Learner knowledge level } & Value \\
\hline 1 & Poor & 1 \\
\hline 2 & Average & 2 \\
\hline 3 & Good & 3 \\
\hline 4 & Very good & 4 \\
\hline 5 & Excellent & 5 \\
\hline
\end{tabular}

3) Content Modelling

We describe the course content as the tree structure with hierarchical nodes that describe topics. They consist of several child nodes. The leaf is a no de without child nodes. These cont ain topic content in detail. Each node includes some attributes to distinguish and they are the basis for adaptation processing. The learner model decides whether node is chosen for different learner or not. It not only decides the numbers of nodes needed to learn but also decides the depth of the tree content that learners are suggested to travel. There a re some reasons why the course content is represented as tree structure instead of knowledge graph that modelled in our recent study, ACGs model $[13,14]$. Those are: (1) The content of our scenario, the learning topic test support is hierarchical structure, (2) The content adaptation for different learner is to select suitable topics from the course so that it examines the tree processing to select nodes required to learn.

We denoted T (Topic) is the subject study, in which $T_{i}$ $(i=1 \ldots n)$ is the subject of the T. Similarly, $T_{i j}(j=1 \ldots m)$ is the child of $\mathrm{T}_{\mathrm{i}}$. The topics are arranged under a tree from top to bottom according to the content of the topic. Each topic is a node of the tree. The topics above ( as in $t$ he general topic) have content that covers the content of the child (a subject in the details.) The child node will inherit the content of the topic at $\mathrm{p}$ arent level. But it is o nly reflected in the general level, not goes into detail on each issue reflected in the topic. It foc used on the content corresponding to its position. This raises the problem of how that can be determ ined in accorda nce with the contents of $\mathrm{t}$ hat topic. B ecause threads are arranged according to each topic, tr ee should have diffe rent altitudes. Depending on such topics as wi de or narrow, there are many issues of co ncern which branches child was born. The principal topics with content relevant to general users have averag e knowledge on that topic. Learners can choose which topics to be able to absorb knowledge in accordance with their capabilities. At the higher topics the content more detail and depth. To be able to learn the $\mathrm{c}$ ontent in these topics, the $\mathrm{s}$ ystem requires students to understand well the content of lower-level topics. This requirem ent is entirely accurate, because the topics at high levels are inherited from the subject at a low level, learner may want to learn and understand the need to have certain knowledge of the problem. This knowledge was assessed through the learning process of users in low-level topics.

\section{4) Learner modelling}

One of the most important information in this layer is learner model that is basic to select adaptive cours e content for different learner. It is designed from context factors as well as learner's knowledge. Because all context factors are re presented by discrete values, the learner model also is described by them. In this model, we assume that learner model depends on context factors and learner knowledge. With context factors, we desi gned learner model whose value is calculated by value of location, concentration and time to learn as showed in Table 3. At this stage of the model, we assu me that the value of learner model is aggregation of al 1 of cont ext factors. Therefore, there are ten $\mathrm{m}$ odels of 1 earners with values from 3 to 12 respectively.

\section{TABLE III. THE VALUE REPRESENTS LEARNER MODEL BASED ON CONTEXT FACTORS: LOCATION, CONCENTRATION AND TIME}

\begin{tabular}{|c|c|c|c|c|c|c|c|c|c|c|c|}
\hline \multicolumn{4}{|c|}{ Low(1) } & \multicolumn{4}{c|}{ Medium (2) } & \multicolumn{4}{c|}{ High (3) } \\
\hline $\mathbf{1 5}$ & $\mathbf{3 0}$ & $\mathbf{4 5}$ & $\mathbf{6 0}$ & $\mathbf{1 5}$ & $\mathbf{3 0}$ & $\mathbf{4 5}$ & $\mathbf{6 0}$ & $\mathbf{1 5}$ & $\mathbf{3 0}$ & $\mathbf{4 5}$ & $\mathbf{6 0}$ \\
$\mathbf{1}$ & $\mathbf{2}$ & $\mathbf{3}$ & $\mathbf{4}$ & $\mathbf{1}$ & $\mathbf{2}$ & $\mathbf{3}$ & $\mathbf{4}$ & $\mathbf{1}$ & $\mathbf{2}$ & $\mathbf{3}$ & $\mathbf{4}$ \\
\hline 3 & 4 & 5 & 6 & 4 & 5 & 6 & 7 & 5 & 6 & 7 & 8 \\
\hline 4 & 5 & 6 & 7 & 5 & 6 & 7 & 8 & 6 & 7 & 8 & 9 \\
\hline 5 & 6 & 7 & 8 & 6 & 7 & 8 & 9 & 7 & 8 & 9 & 10 \\
\hline 6 & 7 & 8 & 9 & 7 & 8 & 9 & 10 & 8 & 9 & 10 & 11 \\
\hline 7 & 8 & 9 & 10 & 8 & 9 & 10 & 11 & 9 & 10 & 11 & 12 \\
\hline
\end{tabular}


Five rows in Table 3 represent the value for location factor, the first ro $\mathrm{w}$ denotes location at Bus terminal which has minimum value and fifth row denotes location at Home which has maximum value. For instance, for the learner who is at home with low concentration level and time to learn is 45 minutes, the learner model value represented in Table 3 is va lue 9 (row 5th and colum $n$ 4th).

As mentioned above, base d on 1 earner's knowledge factor, we def ine learner model as the aggregation of learner model that is based on cont ext and knowledge as shown in Table 4.

TABLE IV. LEARNER MODEL IS COMBINED CONTEXT FACTORS AND LEARNER'S KNOWLEDGE

\begin{tabular}{|c|c|c|c|c|c|}
\hline \multirow{2}{*}{ Learner Model } & \multicolumn{5}{|c|}{ Learner's knowledge } \\
\cline { 2 - 6 } & $\mathbf{1}$ & $\mathbf{2}$ & $\mathbf{3}$ & $\mathbf{4}$ & $\mathbf{5}$ \\
\hline 1 & 2 & 3 & 4 & 5 & 6 \\
\hline 2 & 3 & 4 & 5 & 6 & 7 \\
\hline 3 & 4 & 5 & 6 & 7 & 8 \\
\hline 4 & 5 & 6 & 7 & 8 & 9 \\
\hline 5 & 6 & 7 & 8 & 9 & 10 \\
\hline 6 & 7 & 8 & 9 & 10 & 11 \\
\hline 7 & 8 & 9 & 10 & 11 & 12 \\
\hline 8 & 9 & 10 & 11 & 12 & 13 \\
\hline 9 & 10 & 11 & 12 & 13 & 14 \\
\hline 10 & 11 & 12 & 13 & 14 & 15 \\
\hline
\end{tabular}

There are fourteen models of learner based on learner's knowledge level and context factors. These models are the basis for adaptation layer to select adaptive course content for different learners. For example, if the learner who ca $n$ be at Home, concentration level is Medium, time to learn is 30 minutes and knowledge level is Good (This value is evaluated through the test question when learner participates the course), the learner model value is 11 .

\section{Adaptation layer}

Adaptation layer includes some functions designed to adapt learning materials for each learner. Based on the results of test as well as learner's background, Learner's Knowledge evaluating component used to identify how learner's knowledge level is. Learner modeling component is constructed to determine all of the context factors s uch as location, time to learn, and 1 earner's knowledge of different learners affecting to adaptation. The heart of this layer, learning resource selection component, is used to select appropriate adaptive learning content for each learners according to their learner modeling. We designed several rules to choose learning resources from content model as travelling of $\mathrm{t}$ ree nodes. The child node describes detailed information about parent node. Therefore, if learner travel $s$ the tree deeply, the content obtained is more detailed.

Learning material is adapted to different learners in two ways. The first way is that when learner selects one topic from suggested list, the content belonging to this topic is adapted based on learner model of different learners. The second way occurs when the learners finish a test, the system recommends one or more topics that students need to learn.

We classify student into fourteen categories in order to adapt the course content.
The excerpt we used to select learning resources in this model is if - then rules. The rules as described in the Table 5.

Defended on learner model, the adaptive rules include three elements such as height of tree, number of topic and number of test question.

TABLE V. TABLE 5. ADAPTIVE RULES ACCORDING TO LEARNER MODEL

\begin{tabular}{|c|c|c|c|c|}
\hline \multirow{2}{*}{ No } & \multirow{2}{*}{$\begin{array}{c}\text { Learner } \\
\text { model }\end{array}$} & $\begin{array}{c}\text { Height of } \\
\text { tree }\end{array}$ & $\begin{array}{c}\text { Number of } \\
\text { topic }\end{array}$ & $\begin{array}{c}\text { Number of } \\
\text { test question }\end{array}$ \\
\cline { 3 - 5 } & LM1 & 1 & 1 & 5 \\
\hline 1 & 1 & 2 & 5 \\
\hline 2 & LM2 & 1 & 2 & 5 \\
\hline 3 & LM3 & 1 & 3 & 5 \\
\hline 4 & LM4 & 2 & 3 & 5 \\
\hline 5 & LM5 & 2 & 3 & 10 \\
\hline 6 & LM6 & 3 & 4 & 10 \\
\hline 7 & LM7 & 3 & 4 & 10 \\
\hline 8 & LM8 & 3 & 4 & 10 \\
\hline 9 & LM9 & 4 & 4 & 12 \\
\hline 10 & LM10 & 4 & 5 & 12 \\
\hline 11 & LM11 & 4 & 5 & 12 \\
\hline 12 & LM12 & 5 & 5 & 12 \\
\hline 13 & LM13 & 5 & 5 & 12 \\
\hline 14 & LM14 & 5 & & \\
\hline
\end{tabular}

The height of tree informs that how information is in details. The number of topics denotes the number of child nodes or sub topics of determined topics. Having several sub topics, the number of topics will d ecide how many topics are suppl ied to different learners. Similarly, the number of test questions denotes how many test questions will be required to take after different learners browsing the definite topics.

Adaptation Layer is composed of fou $r$ main components: Adaptive Engine, Adaptive Rule, Context Engine and Context Rule.

\section{1) Context Rule}

This component is a set of rules for handling data and the context in which the Database Layer and Knowledge's Request components provide. The use of rul es for the context will dep end on the requirements of the learner provides. If the request is to provide learning content or assessment tests, the com position will recei ve data from the two components Knowledge's User and Context Data from the Database Layer provides. Correspondingly, if the request is to change $\mathrm{t}$ he level of $\mathrm{k}$ nowledge, the composition will receive data from the Context Data from Database Layer and Knowledge's Request from Detection Layer. After receiving the $\mathrm{c}$ orresponding data from the components, data and the rules which were built before, is executed in the Context Engine component.

\section{2) Context Engine}

Context Engine is the execution of laws on the data context associated with it. The result of this process is to model learning to the learner. The calculation is done as in Table 4.

\section{3) Adaptive Rule and Adaptive Engine}

Adaptive Rule of rule is adapting to each learner model, which is provided by the Database Layer. If the learner model is formed from the required content and knowledge which learners already saved previously, then the law will be applied and processed by the Adaptive Engine 
components as in Table 5. On the other hand, if the learner model is based on a request to change $t$ he assessment of kno wledge on the subject studied, the content model will b e developed based on the corresponding learner model and the number of ran dom course questions. The number of random questions given corresponds to the model of 1 earning and topics that learners want to change the level of assessment. Then, the content model will not include the learning content and height of $t$ ree. To det ermine the degree of difficulty of questions, with it, the determination of the number and level of difficulty of the questions will be based on previous context models and the level should change. Specifically, the context model will prescribe the number of questions that the system will require the learners to answer; specified levels should change the level of difficulty of questions. The number of que stions will be determined by the system default. Meanwhile, the level of difficulty of questions is determined by the ratio between the number of wrong answers $t$ he question and he number of respondents answered the question.

$$
L=\frac{n 1}{n 2} * 100 \%
$$

In which:

$$
\begin{aligned}
& \text { - L: Level of difficulty of a question } \\
& \text { - n1: Number of wrong answers that question } \\
& \text { - n2: Number of people answered that question }
\end{aligned}
$$

For example: With a question has:

$\mathrm{n} 1=200 ; \mathrm{n} 2=500$; Then, $\mathrm{L}=(200 / 500) * 100 \%=40 \%$.

Because the le vel of need to change cove rs only the value: Poor (1), Average (2), Good (3), Very Good (4), Excellent (5), we will d etermine the level of difficulty corresponding to the ratio between the Poor $[0 \%, 20 \%)$, Average $[20 \%, 40 \%)$, Good $[40 \%, 60 \%)$, Very Good

\begin{tabular}{|c|c|c|c|c|c|c|}
\hline \multirow{2}{*}{$\begin{array}{c}\text { Learner } \\
\text { Model }\end{array}$} & \multirow{2}{*}{$\begin{array}{c}\text { Number } \\
\text { of test } \\
\text { question }\end{array}$} & \multicolumn{5}{|c|}{ Knowledge's Request } \\
\hline & & 1 & 2 & 3 & 4 & 5 \\
\hline 1 & 10 & \multirow{10}{*}{$\begin{array}{c}{[0 \%, 20} \\
\%)\end{array}$} & \multirow{10}{*}{$\begin{array}{c}{[20 \%, 4} \\
0 \%)\end{array}$} & \multirow{10}{*}{$\begin{array}{c}{[40 \%, 6} \\
0 \%)\end{array}$} & \multirow{10}{*}{$\begin{array}{l}{[60 \%,} \\
80 \%)\end{array}$} & \multirow{10}{*}{$\begin{array}{c}{[80 \%, 10} \\
0 \%]\end{array}$} \\
\hline 2 & 10 & & & & & \\
\hline 3 & 10 & & & & & \\
\hline 4 & 10 & & & & & \\
\hline 5 & 10 & & & & & \\
\hline 6 & 10 & & & & & \\
\hline 7 & 10 & & & & & \\
\hline 8 & 10 & & & & & \\
\hline 9 & 10 & & & & & \\
\hline 10 & 10 & & & & & \\
\hline
\end{tabular}
$[60 \%, 80 \%)$, Excellent $[80 \%, 100 \%]$. Speci fically, we have the following Table 6 :

TABLE VI. CONTENT MODEL AS A CHANGE OF LEARNER

The questions will be taken randomly in the ratio range them. For example: Originally, the user selects the context values: Location (home), time (30 minute), concentration (medium) and Topic is Noun . Then, the user com pleted and evaluated: level of knowledge is Average. The user wants to change this rating to Good. Meanwhile, the number of q uestions the system offers is 10 a nd the difficulty of the questions are in the interval [40\%-60\%).

\section{SYSTEM PROTOTYPE IMPLEMENTATION}

We implemented CAMLES prototype based on J2ME technology. Therefore, mobile phone needs to support java program as well as GPR S or $3 \mathrm{G}$. In order to use CAMLES, the learners need to download and install application themselves in their mobile phone. At th is stage, we de velop content model which consists of five main topics: Noun, Verb, Adjectives, Adverbs and Prepositions. Those are considered as parent topics for the entire contents of the system. Under each topic, there will be a corresponding child topic, for example, the child of Adjectives topic has eight ch ildren: Manner, Place, Time, Frequency, Sentence, Degree, Interrogative and Relative.

The learner inputs context parameters via mobile interface. The topic content was adapted him. Finishing this topic, the system suggests some question test to evaluate learner's knowledge of the topic and shows the test results as well as recommendations in next screen.

For example, first, students will choose the context, including Time (10 minute), Location (Home) and Concentration (High). Then they will select Topic (Noun). Based on the context and topic, the system will give back to learning content, respectively, as Figure 2.

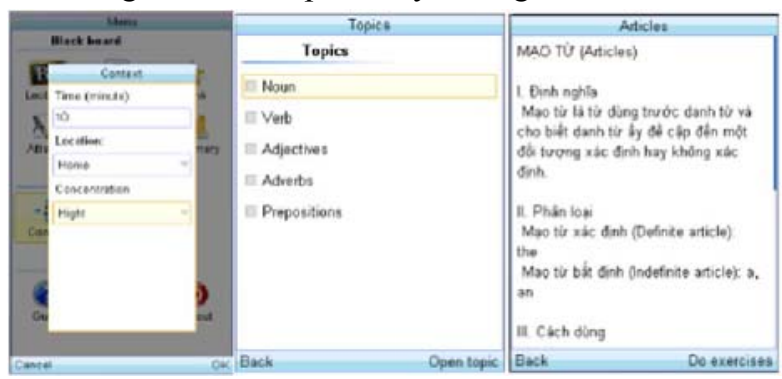

Figure 2. Learner inputs context parameters and adaptive content showed

After that, learners were unsure about their knowledge of course content that the system offers, learners will have to complete the questions that the system provides, as Figure 3 .

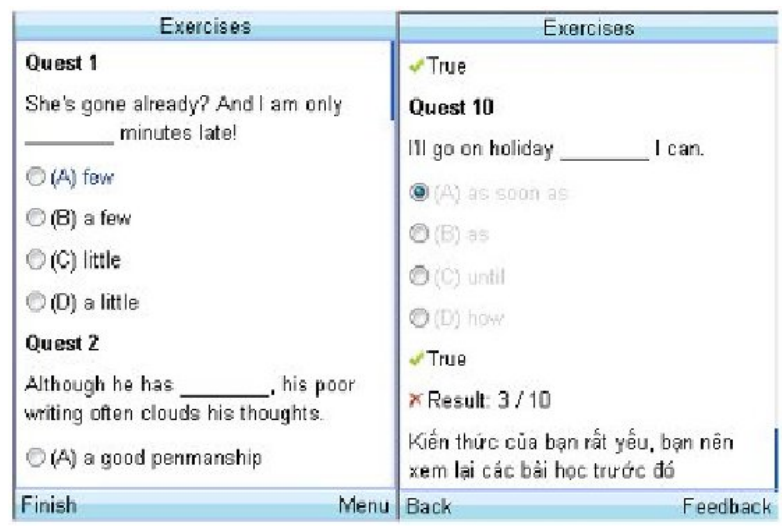

Figure 3. Test questions for evaluating learner's knowledge

End of t est questions evaluating the system requires learners to perform, the system will evaluate and respond 
to learners. The study could change the evaluation of the system on their own knowledge, as in Figure 4.

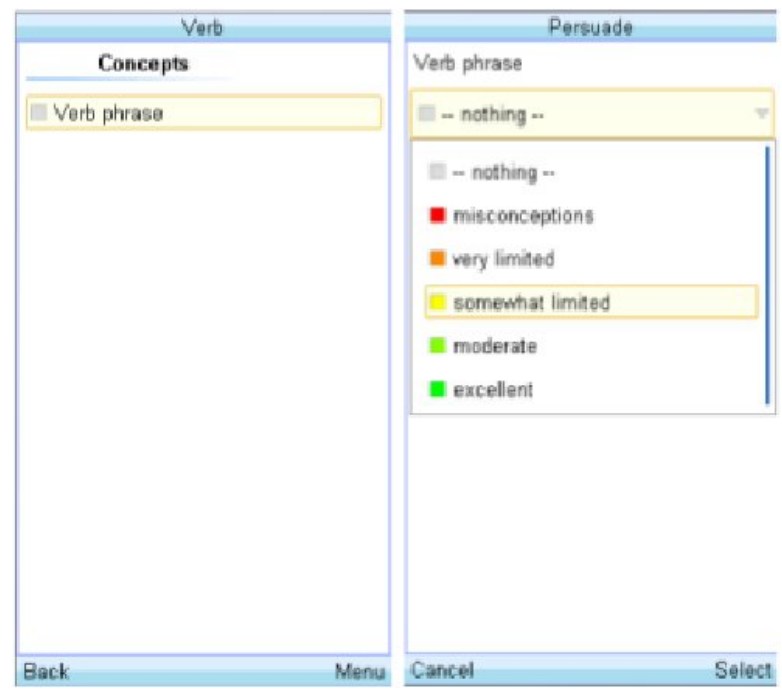

Figure 4. The learner evaluated changes in the knowledge that the system was evaluated

After the learner has cha nged the knowledge level assessment system that has been evaluated, the syste $\mathrm{m}$ will provide the learner some questions to confirm that the change of the course is true. Therefore, students will have to complete all the questions. If learn ers complete the right amount of questions in the rate that the system can accept, then students will be accepted that the knowledge itself has changed. Conversely, if learners do not complete the questions, the system will re-evaluate the level of knowledge of the learning results that learners have achieved. The change in the evaluation and testing will stop when they have ac cepted the assessment of knowledge that the system offers, such as in Figure 5.

Quest 1
My brother plays his records
nobody can gis room at night, and
(A) at full tilt
(B) in full swing
(C) at full blast
(D) in full cry
Quest 2
Our guest of honour arrived rather
late. The party was alrody
O(A) in full swing
(B) an full tilt
(C) in full bloom
(D) to the full
Finish

Figure 5. Questions that learners should complete the questions and assessing knowledge levels were changed after completing the questions

To examine our experimentation, we desi gned a questionnaire which i ncludes six questions in order to survey 35 students who used CAMLES system with their mobile phones which support GPRS or $3 \mathrm{G}$ to connect to Internet. In order to evaluate our system, students check to one of from 1 to 5 values that 1 was the lowest and 5 was the highest. We classify students into three categories: group one includes students who ha ve never taken the TOEFL test before, group two contain students who have taken TOEFL test and have got below 450 score (paper test), and grou $p$ three are student $s$ have re ceived above 500 score. Table $7 \mathrm{sh}$ own average results of $\mathrm{t}$ he questionnaire for each group.

TABLE VII. RESULT S OF QUESTION-NAIRE

\begin{tabular}{|c|l|c|c|c|}
\hline No & \multicolumn{1}{|c|}{ Question } & G1 & G2 & G3 \\
\hline 1 & $\begin{array}{l}\text { Do you think the system was easy to } \\
\text { use? }\end{array}$ & 3.5 & 4.0 & 4.0 \\
\hline 2 & $\begin{array}{l}\text { Would you like to use the sy stem } \\
\text { again? }\end{array}$ & 4.5 & 4.0 & 3.5 \\
\hline 3 & $\begin{array}{l}\text { Do you think the test question i s } \\
\text { appropriate for you? }\end{array}$ & 3.0 & 4.5 & 4.0 \\
\hline 4 & $\begin{array}{l}\text { The topic that syste m selects is } \\
\text { appropriate for you? }\end{array}$ & 4.5 & 4.0 & 3.5 \\
\hline 5 & $\begin{array}{l}\text { Did you choose context factors as } \\
\text { you in? }\end{array}$ & 3.0 & 4.5 & 5.0 \\
\hline
\end{tabular}

According to Question 1 and Question 2, the students were satisfied with system and would like to use the system again. $R$ esults of Quest ion 3 sh owed that the students who have never taken TOEFL test before did not satisfy because the test questions, which we used in prototype, are not easy. The results of this question also denote that the students, who have had high test scores before, satisfied with system. Average score of Question 4 is 3.5 denoting that the topic selected for such students is not good enough because our content model does not have more topic as well a s topic content is $n$ ot in details to support them. Question 5 surveys learners who choose the context whether true as they in or not. For instance, the learners can choose their loca tion at home while they are at Bus ter minal. Problem of how to locate learner' $s$ location will be resolved in the next stage through location base services. As you see, in Group 1 result, students who have never take the TOEFL test before are in terested in our system. However, Average score of Question 5 is 3.0 showing that they often choose the context which is not true as they in. For example, they choose $\mathrm{R}$ estaurant location while they are in class.

\section{DISCUSSIONS}

Our target users are graduate students who intend to take TOEFL test. However, this approach can be applied to general learners to study English as a foreign language. Our model, context-aware location-dependent learning, adapts learning content according to c ontext as well as learner's knowledge background. To find interests in our system, we compare it with early systems.

In TenseITS [3], learner's knowledge parameter is only calculated at current stage, so if the learner, from second time, backs to the system with the same context factors as he/she inputted previously, the adaptive contents are similar. In our model, learner's knowledge background is stored and is evaluated after the students finish the topic. The results are basic for re calculating value of learner model for next time when learners use system.

The CAMLL [2] is also based on learner level to adapt suitable sentences, however, how the learner's level updating learning progress has not been specified.

At this stage, our learner model is still not distinct for all context cases. Therefore, there are several d ifferent contexts having the same value in learner's model. In the 
future work, we will consider refining the content model as well as adaptive engine $\mathrm{i} n$ order to $\mathrm{m}$ atch the learner's requests. One notable problem of how to fragment content to display in accordance with the size of the mobile phone is also considered. In addition, we will improve user interface to meet demands of new use rs. We intend to deploy a web application version of this model because of the disadvantages of the stand -alone application. The web application easily supports different models of $m$ obile phones.

\section{CONCLUSIONS}

This work represented a personalized context-aware mobile learning architecture. By using open 1 earner modeling technique, this model allows learners to interact with the syste $m$ in order to get accurate actual learner's demands. In order to do $t$ hat, we al so proposed an adaptation mechanism based on e valuating learner's knowledge to select adaptive learning materials meet the learners. Besides, prototype of use was presented to illustrate the potential of applicability of our system.

\section{VIII.REFERENCES}

[1] N. V. Anh, P. V. Cong, and H. S. Dam. A Context-A ware Mobile Learning Adaptive System for Suppor ting Foreigner Learning English. In Pro ceedings of IEEE-RIVF 2010 International Conference on Co mputing and T elecommunication Technologies, 2010.

[2] K. Al-Mekhlafi, X. Hu, and Z. Zheng. An ap proach to co ntextaware mobile chinese language lea rning for foreign students. In Proceedings of the 2009 Eighth International Conference on Mobile Business, pages 340-346, Washington, DC, USA, 2009. IEEE Computer Society. http://dx.doi.org/10.1109/ICMB.2009.65

[3] Y. Cui and S. Bull. Context and learner modelling for the mobile foreign language learner. volume 33, pages 353-367, 2005.

[4] R. G. J. P aredes, H. Ogata, A. Nobuji, Y. Oishi, and T. Ueda. Loch: Supporting informal language learning outside the classroom with handhelds. In WMTE'05, pages 182-186, 2005.

[5] C.-M. Chen, Y.-L. Li, an d M.-C. Chen. Personalized contextaware ubiquitous learning system for supporting effectively english vocabulary learning. In ICALT'07, pages 628-630, 2007.
[6] H. Ogata and Y. Yano. Context-aware support for computersupported ubiquitous learning. In WMTE'04, pages 27-34, 2004.

[7] [6] M. LI, H. OGAT A, S. HA SHIMOTO, and Y. YANO. Adaptive kanji learning using mobile-based email. pages 520-526, 2009.

[8] S. A. Petersen, J.-K. Markiewicz, and S. S. BjØrnebekk. Personalized and contextualized language learning: Choose when, where and what. Research and Practice in Technology Enhanced Learning, pages 33-60, 2009.

[9] A. K. Dey. Providing architectural support for building contextaware applications. Atlanta, GA, USA, 2000. Georgia Institute of Technology.

[10] B. Hu and P. Moore. "smart context": An ontology based context model for cooperative mobile learning. In CSCWD (Selected Papers)'06, pages 717-726, 2006.

[11] G. D. Abowd, A. K. Dey, P. J. Brown, N. Davies, M. Smith, and P. Steggles. Towards a better understanding of context and context-awareness. In HUC'99, pages 304-307, 1999.

[12] T. Reichenbacher. Adaptive methods for mobile cartography. ICC 2003, (August):10-16, 2003.

[13] N. V. Anh and H. S. Da m. Acgs: Adaptive cour se generation system - an ef ficient approach to build e-learning course. In Proceedings of the IEEE $S$ ixth International Conference on Computers and Information Technology, pages 259-265, 2006.

[14] N. V. Anh, N. V. Ha, and H. S. Dam. Developing adaptive hypermedia system based on learning design level $b$ with rules for adaptive learning activities. Journal of Natural Science, Vietnam Nation University, 25(1):1-12, 2009.

\section{AUTHORS}

Viet Anh NGUYEN is with the University of Engineering and Technology, VNU, E3, 144 XuanThuy, CauGiay, Hanoi, Vietnam (email: vietanh@vnu.edu.vn).

Van Cong PHAM is with the University of Engineering and Technology, VNU, E3, 144 XuanThuy, CauGiay, Hanoi, Vietnam (email: vcong.pham@gmail.com).

This work has been supported by the research project No QG.11.33 of Vietnam National University. Received 15 August 2011. Published as resubmitted by the authors 27 September 2011 . 